\title{
Gerenciamento de casos como estratégia de trabalho para a enfermagem psiquiátrica comunitária*
}

\author{
CASE MANAGEMENT AS A WORK STRATEGY FOR COMMUNITY PSYCHIATRIC NURSING \\ GERENCIAMIENTO DE CASOS COMO ESTRATEGIADE TRABAJO \\ PARALAENFERMERÍA PSIQUIÁTRICACOMUNITÁRIA
}

\author{
Amanda Márcia dos Santos ${ }^{1}$, Margarita Antônia Villar Luis ${ }^{2}$
}

\footnotetext{
* Nota prévia de Tese de Doutoramento junto ao Programa de Pós-Graduação em Enfermagem Psiquiátrica da Escola de Enfermagem de Ribeirão Preto da Universidade de São Paulo (EERPUSP), em curso desde julho de 2003 com previsão de término em junho de 2005.

1 Doutoranda do Programa de Pós-Graduação em Enfermagem Psiquiátrica da EERP-USP.Docente do Departamento de Enfermagem das Faculdades Federais Integradas de Diamantina. amsreinaldo@hotmail.com

2 Docente do Departamento de Enfermagem Psiquiátrica e Ciências Humanas da EERP-USP
}

A Organização Mundial de Saúde prevê que a porcentagem da morbidade mundial atribuída aos transtornos mentais e de comportamento aumente de $12 \%$, verificada no ano de 1999, para $15 \%$ no ano de 2020. Esse aumento será particularmente pronunciado nos países em desenvolvimento, devido ao envelhecimento da população e a rápida urbanização. As repercussões sociais e econômicas e a perda da produção devido às altas taxas de desemprego entre as pessoas com transtornos mentais e seus cuidadores, são alguns dos custos mais evidentes e mensuráveis dessa projeção, menos evidentes resultam a redução da qualidade de vida e a tensão emocional sofrida pelos pacientes e suas famílias. O gerenciamento de casos contrapõese ao hospital psiquiátrico tradicional e constitui uma alternativa para a atenção à saúde mental que se mostrou viável e possível em alguns países e baseia-se no preparo do doente mental enquanto responsável pelo seu cuidado e por mantê-lo na comunidade em contato com o serviço, mas não dependendo dele; desenvolvendo relações entre seus pares sem a necessidade constante de intervenção. O objetivo geral deste estudo é expandir o campo de atuação do enfermeiro psiquiátrico, no que se refere ao tratamento e acompanhamento do paciente psiquiátrico na comunidade, considerando o conceito de gerenciamento de casos e seus pressupostos, visando sua utilização em serviços de saúde mental que trabalhem no referencial da reforma psiquiátrica. Este estudo configura-se como qualitativo, utilizamos a estratégia de estudo de caso para coleta dos dados. Os dados foram coletados no período de oito de setembro de 2003 a oito de março de 2004, na Unidade de Emergência Psiquiátrica do Hospital das Clínicas da Faculdade de Medicina de Ribeirão Preto da Universidade de São Paulo (UE-HCFMRP-USP) e posteriormente no domicílio dos pacientes que compuseram nossa população. A população foi composta pelos pacientes que procuraram atendimento na UE-HCFMRP-USP, no período de oito de setembro a sete de outubro de 2003. Ao final de um mês, 20 pacientes foram selecionados para participarem da pesquisa. Utilizamos o gerenciamento de casos comunitário e intensivo, do tipo clínico com ênfase nas dificuldades apresentadas pelos pacientes. A coleta dos dados teve início após a aprovação pelo Comitê de Ética em Pesquisa da referida instituição. No momento estamos realizando a análise dos resultados, que preliminarmente, nos mostram que apesar de todos os avanços na área da psiquiatria o paciente psiquiátrico ainda tem sofrido com o estigma da doença mental, as incapacidades associadas aos sintomas residuais que não são contempladas, a inexistência de projetos terapêuticos para essa pessoas e a falta de articulação dos serviços de saúde mental, que se denomina rede, mas que, não trabalha como tal. Dentre outros desdobramentos do estudo, inclui-se o de oferecer aos enfermeiros psiquiátricos da assistência e do ensino um repertório de possibilidades de trabalho com o doente mental e que ampliem sua autonomia, dado que isso também integra as ações do cuidar. 